\title{
Alternating facial paralysis in a girl with hypertension. Case report
}

\author{
Özlem Bă̆ $M D^{a}$, Utku Karaarslan $M D^{a}$, Sezer Acar $M D^{a}$, Rana İşgüder $M D^{a}$, Aycan Ünalp MD Assoc. Prof. ${ }^{b}$ \\ and Aysel Öztürk $M D^{b}$
}

\begin{abstract}
Bell's palsy is the most common cause of acquried unilateral facial nerve palsy in childhood. Although the diagnosis depends on the exclusion of less common causes such as infectious, traumatic, malignancy associated and hypertension associated etiologies, pediatricians tend to diagnose idiopatic Bell's palsy whenever a child admits with acquired facial weakness. In this report, we present an eight year old girl, presenting with reccurent and alternant facial palsy as the first symptom of systemic hypertension. Shehad underwent steroid treatment without measuring blood pressure that could worsen hypertension. Clinicians should be aware of this association and not neglect to measure the blood pressure before considering steroid therapy for Bell's palsy. In addition, the less common causes of acquired facial palsy should be kept in mind, especially when reccurent and alternant courses occur.

Key words: Bell's palsy, hypertension, childhood, steroid.
\end{abstract}

http:/ /dx.doi.org/10.5546/aap.2013.e133

\section{INTRODUCTION}

Acquried facial nerve palsy is an uncommon problem in childhood, affecting 2.7-10.1 children per 100,000 annualy. ${ }^{1}$ Although infectious, traumatic, malignancy associated and hypertension associated etiologies has been reported, ${ }^{2}$ the most common cause of acute unilateral facial weakness is Bell's palsy accounting for $60-75 \%$ of cases. ${ }^{3}$ Recent studies reported that Bell's palsy consist of $9-16 \%$ of cases in pediatric age. ${ }^{4}$ Despite the fact that the diagnosis of Bell's palsy depends on exclusion of other etiologic factors and relatively lower rate in childhood, pediatricians tend to diagnose Bell's

a. Department of Pediatrics.

b. Department of Pediatric Neurology.

Research and Teaching Bord. Behçet Uz Children's Hospital. Alsancak, İzmir, Turkey.

E-mail address:

Özlem Bă̆ MD: bagozlem78@yahoo.com

Conflict of interest:

None.

Received: 6-6-2013

Accepted: 7-1-2013 palsy whenever a child admits with unilateral facial weakness and treat with corticosteroid drugs with or without an antiviral medication. However, a detailed clinical history and a complete clinical examination is required in differential diagnosis.

\section{CASE REPORT}

An eight year old girl was referred to our clinics with alternant lower motor neuron facial nerve palsy. She was previously healty until she was diagnosed with Bell's palsy two months ago when she admitted with facial asymmetry and inability to close the right eye and a short course of prednisone was initiated after acute otitis media was excluded. Her symptoms had gradually decreased in a few weeks but had repeated on the other side of her face. During this period, magnetic resonance imaging (MRI) was performed in order to exclude a brainstem lesion but a blood pressure measuring was neglected. Her mother was obese and hypertensive and was under control with two antihypertensive drugs. On admission, she was conscious and orientated with a blood pressure of 160/100 $\mathrm{mmHg}$; >95 p for age and sex. She was $42 \mathrm{~kg}$, so obese with 22.4 body mass index; $>95 \mathrm{p}$ for age and sex. Neurological examination revealed a lower motor neuron facial palsy on the left side of the face. Other physical and neurological findings were normal. All laboratory tests, including complete blood count, urinalysis, blood urea nitrogen, serum creatinine, electrolytes, renin - aldosterone and cortisol levels were in normal range. Renal and renal doppler ultrasonography were normal excluding renal and renovascular causes while echocardiography revealed an increased left ventricule mass index $\left(42.5 \mathrm{~g} / \mathrm{m}^{2},>95 \mathrm{p}\right.$ for height and sex) due to chronic hypertension but excluded a coarctation of aorta. As all laboratory and radiologic investigations excluded secondary hypertension due to renal, renovascular, cardiac and endocrinologic causes, she was diagnosed with essential hypertension depending on obesity and family history. She was treated with amlodipine (5 mg/day) and lower motor neuron 
facial palsy resolved in a few days. But she required an incresed dose $(10 \mathrm{mg} /$ day) to reduce blood pressure to less than $90^{\text {th }}$ percentile. She was discharged home without any neurological finding after her blood pressure was under control. In 6 months follow up, she had no symptoms of hypertension and blood pressure control was achieved with single agent.

\section{DISCUSSION}

Moxon was the first to describe the association between hypertension and lower motor neuron facial nerve palsy. ${ }^{5} \mathrm{He}$ described a patient with facial weakness in the setting of renal disease and reported necropsy findings in 1869. Since then, several reports documented this association in both adults and children. In 1933, Griffith reviewed the published reports, and described 6 adults and 3 children with facial nerve palsy and hypertension. ${ }^{6}$ Furthermore, in following years, facial palsy was reported to be the first and only symptom of hypertension, ${ }^{7,8}$ as seen in our case.

The frequency of facial palsy in hypertension is controversial in literature. Pediatric case series from 1960's reported the presence of facial palsy in severe hypertension $20 \%$ and $11 \%$, respectively. ${ }^{7,9}$ In contrast, a study of 190 adult patients reported presence of isolated facial nerve palsy in only $2.6 \%$ of the subjects. ${ }^{10}$ Interestingly, the majority of this association is reported in pediatric population. ${ }^{7,9}$ From another point of view, hypertension is attributed to only $5.4 \%$ of acquired facial palsy. ${ }^{11}$

In recent years, Kim et $\mathrm{al}^{12}$ reported bilateral facial nerve palsy in seven cases and defined bilateral simultaneous facial nerve involving both sides of the face within 4 weeks. Our case was not evaluated to be bilateral as there was 8 weeks between two attacks of her complaints. Although bilateral simultaneous facial palsy is uncommon (0.3- $2 \%)$, there is lack of data on frequency of alternating course. There are several case reports documenting alternant facial palsy in childhood. ${ }^{13,14}$ Oosterveer, et al. have previously reported that in case of recurrent or bilateral facial palsy, diagnoses other than Bell's palsy should be considered.$^{15}$ The differential diagnosis consist of infections, inflammatory conditions, injuries, neoplasies, genetic- metabolic diseases, and other systemic diseases including arteriel hypertension. In our case, the alternant course pointed out a systemic disease other than local causes and she was diagnosed with childhood hypertension by serial monitoring of blood pressure.
The pathogenesis of hypertension induced facial palsy is not well understood. As a matter of fact, vascular lesions are a well known complication of hypertension and may occur among the course of the nerve. However, the lesion in all the reported cases was a lower motor neuron facial palsy indicating a lesion between the facial nucleus in the brainstem and the exit of the nerve at the stylomastoid foramen. Autopsy findings of two previously reported cases revealed blood clots in the facial canal, ${ }^{5,7}$ suggesting a haematoma or thrombus due to increased arteriolar injury leading facial nerve compression. Another hypothesis is that widespread vessel thickness due to hypertension and perineural oedema has a pressure effect itself on facial nerve, mimicking other nerve compression syndromes. Alternant facial palsy and clinical response to first course of steroid therapy may suggest an oedema etiology in our case. In fact, steroid therapy becomes contraindicated in case of malignant hypertension but antioedema effect may have resulted in clinical remission.

In conclusion, unilateral facial nerve palsy may be a symptom, particularly the first symptom of hypertension. Clinicians should be aware of this association and not neglect to measure the blood pressure before considering steroid therapy for Bell's palsy that may worsen hypertension. Specially, a systemic disease is highly suspicious when alternant and reccurent facial palsy occurs.

\section{REFERENCES}

1. Rownlands S, Hooper R, Hughes R, et al. The epidemiology and treatment of Bell's palsy in the UK. Eur J Neurol 2002;9:63-7.

2. Lorch M, Teach SJ. Facial nerve palsy: etiology and approach to diagnosis and treatment. Pediatr Emerg Care 2010;26(10):763-9; quiz 770-3.

3. Gilden DH. Clinical practice. Bell's Palsy. N Engl J Med 2004;351(13):1323-31.

4. Evans AK, LicameliG, BrietzkeS, Whittemore K, Kenna M. Pediatric facial nerve paralysis: patients, management and outcomes. Int J Pediatr Otorhinolaryngol 2005;69(11):1521-8.

5. Moxon M. Apoplexy into canal of Fallopius in a case of Bright's disease causing facial paralysis. Trans Path Soc London 1869;20:420-2.

6. Griffith, JQJr. Involvement of the facial nerve in malignant hypertension. Arch Neurol (Chicago)1993;29:1195.

7. Lloyd AV, Jewitt DE, Still JD. Facial paralysis in children with hypertension. Arch Dis Child 1966;41(217):292-4.

8. Siegler RL, Brewer ED, Corneli HM, Thompson JA. Hypertension first seen asfacial paralysis: case reports and review of the literature. Pediatrics 1991;87(3):387.

9. Trompeter RS, Smith RL, Hoare RD, Neville BG, et al. Neurological complications of arterial hypertension. Arch Dis Child 1982;57:913-7.

10. Clarke E, Murphy EA. Neurological manifestations of 
malignant hypertension. Brit Med J 1956;2:1319-26.

11. Paine RS. Facial paralysis in children: Review of differential diagnosis and report of 10 cases treated with cortisone. Pediatrics 1957;19:303.

12. Kim YH, Choi IJ, Kim HM, et al. Bilateral simultaneous facial nerve palsy: Clinical analysis in seven cases. Otol Neurotol 2008;29:397-400.

13. Harms MM, Rotteveel JJ, Kar NC, Gabreëls FJ. Recurrent alternating facial paralysis and malignant hypertension. Neuropediatrics 2000;31:318-20

14. Aynaci FM, Sen Y. Peripheral facial paralysis as initial manifestation of hypertension in a child. Turk J Pediatr 2002;44:73-5.

15. Oosterveer DM, Bénit CP, de Schryver EL. Differential diagnosis of recurrentor bilateral peripheral facial palsy. J Laryngol Otol 2012;126(8):833-6. 